\title{
An Epidemiological Study of Gastroesophageal Reflux Disease and Related Risk Factors in Urban Population of Mashhad, Iran
}

\author{
Hassan Vossoughinia ${ }^{1}$; Masoumeh Salari ${ }^{1}$; Elham Mokhtari Amirmajdi ${ }^{2}$; Hassan Saadatnia ${ }^{1}$; \\ Siavash Abedini ${ }^{1}$;Alireza Shariati ${ }^{1}$; Mohammadjavad Shariati ${ }^{1}$; Ahmad Khosravi Khorashad ${ }^{1, *}$ \\ ${ }^{1}$ Department of Internal Medicine, Mashhad University of Medical Sciences, Mashhad, IR Iran \\ ${ }^{2}$ Faculty of Medical Sciences, Nayshabur University of Medical Sciences, Nayshabur, IR Iran \\ *Corresponding Author: Ahmad Khosravi Khorashad, Department of Internal Medicine, Mashhad University of Medical Sciences, Mashhad, IR Iran. Tel:+98-5138012742, Fax: +98- \\ 5138453239, E-mail: Khosravia@mums.ac.ir
}

Received: October 31, 2013; Revised: September 6, 2014; Accepted: October 28, 2014

\begin{abstract}
Background: Gastroesophageal Reflux Disease (GERD) is a chronic and common disease, which is characterized by heartburn and regurgitation. In the last couple of decades, GERD has received much attention and studies have shown an increase in its prevalence. Although there have been a few studies on the prevalence of GERD in Iran, no study has yet been done in the northeastern part of the country. The aim of our study was to evaluate the prevalence of GERD and its risk factors in a population from Mashhad.

Objectives: To evaluate the epidemiology of GERD based on a population study in Mashhad.

Patients and Methods: This was a cross sectional descriptive study conducted in 2010. In total, 2500 participants were selected based on cluster sampling. Modified and validated Mayo Clinic questionnaire for GERD was used for data collection. Overall, 1685 questionnaires were retrieved. Fifty-one participants were excluded because of pregnancies, history of abdominal surgery and being less than 18 years old. We analyzed data using the SPSS software version 16. Prevalence of GERD and significant risk factors (P value $<0.05$ ) were determined. Results: In total, 420 participants (25.7\%) had GERD symptoms. Risk factors with significant effects consisted of smoking, consumption of non-steroidal anti-inflammatory drugs (NASIDs), overeating, chronic diseases, tea and coffee consumption and GERD in spouse. Conclusions: The prevalence of GERD among people living in Mashhad was above the average prevalence in other cities of Iran. However, risk factors seemed to be similar to those reported by other studies.
\end{abstract}

Keywords:Gastroesophageal Reflux; Risk Factors; Gastroesophageal Reflux Disease; Iran

\section{Background}

Gastroesophageal reflux disease (GERD) is a common chronic and recurrent gastrointestinal problem worldwide, especially in the west $(1,2)$. It is defined by the abnormal reflux of gastroduodenal content into the esophagus, occurring on a daily, weekly or yearly basis, which may lead to other complications including esophagitis, esophageal ulcer, upper gastrointestinal bleeding and Barrett`s esophagus (3-5). In all previous studies the number of occurrences, time and severity are considered. However, one of the problems with the epidemiological study of reflux disease has always been the lack of a comprehensive and standard definition for the disease. Consequently, the actual prevalence and incidence of reflux disease are unknown due to the lack of such definition and insufficient population based studies $(6,7)$. In several epidemiological studies, the weekly prevalence of reflux disease in developed countries has been reported to range from $10 \%$ to 48 $\%$. About $44 \%$ of Americans experience the symptoms of reflux at least once a month, with $20 \%$ and $7 \%$ having weekly and daily reflux, respectively (7). Retrograde endoscopic -based studies performed by Rothmen and Malekzadeh, from 1994 to 1999, showed a threefold increase in the prevalence of reflux disease from 20 to $70 \%$.

Population-based studies have shown that the prevalence of GERD has been increasing in developing Caucasian countries such as Iran. Reflux is more common in Arab countries than in non-Arabian Asian countries; the prevalence of weekly reflux in East Asian countries is reported to be between $2.5 \%$ and $20 \%$ (8-10). In Iran, reflux has increased in frequency over the last two decades (11, 12). Unfortunately, the cost of long-term medical therapy is substantial, for instance approximately eight billion dollars and 46 million pounds were spent to treat GERD in US and United Kingdom during the year 2000, respectively (13). The weekly prevalence of reflux in Iran, based on different studies, ranges from $6 \%$ to $33 \%$. This wide range of prevalence reported for GERD is mainly due to the different methodologies or definitions implemented in the studies of GERD.

In patients with GERD, both the physical and psycho-

Copyright ( ) 2014, Iranian Red Crescent Medical Journal. This is an open-access article distributed under the terms of the Creative Commons Attribution-NonCommercial 4.0 International License (http://creativecommons.org/licenses/by-nc/4.0/) which permits copy and redistribute the material just in noncommercial usages, provided the original work is properly cited. 
social aspects of life are impaired. There is a significant correlation between a depressed sense of well-being and the severity of GERD $(14,15)$. In Iran, significantly different prevalence rates for GERD have been reported by different studies, reflecting the varying methodologies and definitions implemented (16-20). Body mass index (BMI) is a risk factor for GERD, yet weight loss does not improve the disease. The effect of gender is controversial; i.e., several studies have shown a high prevalence in men, while others have reported no gender differences. Other potential risk factors include asthma, a positive history of GERD in first-degree relatives and spouse, lower levels of education and socioeconomic status, coffee, tea and alcohol consumption, smoking, and consumption of nonsteroidal anti-inflammatory drugs $(1,17,21)$.

\section{Objectives}

The aim of this study was to assess the epidemiology of GERD and its risk factors according to a population based study in Mashhad, which is the second largest city of Iran after the capital city.

\section{Patients and Methods}

This study was a cross sectional analysis conducted during 2010. The sample size was calculated as 2500. Cluster sampling was performed in 50 city locations based on electrical code area and 50 participants were included for each location. In total, 1685 questionnaires were retrieved. Fifty-one out of 1685 had less than 18 years of age, were pregnant, had a history of abdominal surgery, had a coincidental disease including malignancies or consumed drugs which might influence the outcome of the study and thus were excluded.

The original questionnaire was obtained from the Mayo Clinic with permission; this questionnaire was distributed as a pilot study in a limited population and its validity was checked. The questionnaire covered demographic characteristics, major and minor symptoms of GERD plus their severity. The study was initiated by dividing the city of Mashhad geographically into fifty areas. Subsequently, fifty questionnaires were distributed randomly in each of the areas. The Research Ethics Committee of Mashhad University of Medical Sciences approved the study with ethical code of 89365 . Data collection was done by distributing the questionnaires around the city and collecting them during the following days. Trained medical students were recruited to handle possible confusion regarding the questions. People with at least one week of reflux symptoms over the past year were included in the reflux group. The SPSS software version 16 was used for statistical analysis. A P value of 0.05 or less was considered statistically significant. All reported P values were two sided using the chi-square test.

\section{Results}

Approximately $60 \%$ of the questionnaires were collect- ed during the first referral after 24 hours. Others were retrieved during the other days of follow up. Totally, 1685 questionnaires were collected, 51 of which were excluded as the participants were pregnant (22), had a past history of surgery (23) or were below 18 years of age. Overall, 9.8\% of the questions were left without any response. Fifty-six percent of the responders were female and $44 \%$ were male. The mean age was $38.7 \pm 15$ years with a male to female ratio of $1.3 / 1$. The nonparametric Mann-Whitney test showed a normal distribution for age. From the total of 1634 respondents only 420 people (25.7\%), who were considered as the reflux group, had reflux symptoms once or more times a week over the past one year. The remaining subjects were included in a second group termed the non-reflux group. Therefore, the prevalence of reflux in Mashhad was estimated at 25.7\% (Figure 1).

The frequency of GERD symptoms was different in our population compared to previous reports. In our study the most common symptom was the concomitant occurrence of heartburn and regurgitation reported in $29.5 \%$, followed by regurgitation as a single complaint in 25.7\%. Subjects were categorized into four groups based on symptom severity. Those who experienced symptoms only when thinking about it were regarded as having mild symptoms. Those having symptoms of heartburn or regurgitation without major effects on their job or life style were considered as severe. Interruption of normal life was considered as very severe symptoms. Most subjects had moderate symptoms (66\%). Symptoms were also categorized based on their frequency of occurrence; once every two or three weeks, once a week, two or three times a week, daily and several times a day. Of the 897 cases with a history of reflux during the previous year, $43.4 \%$ experienced symptoms once every two or three weeks, $13 \%$ weekly, $20.4 \%$ two or three times a week, $7.6 \%$ daily, and $5.8 \%$ more than once a day. In the reflux group, $27.9 \%$ had weekly symptoms, $43.6 \%$ experienced symptoms two or three times a week, $16.1 \%$ had daily complaints and $12.35 \%$ reported reflux several times a day (Figure 2). In the same group of patients, 55\% sought medical consultation for their reflux symptoms, $98.7 \%$ of whom were prescribed medication. Of these, $93.9 \%$ consumed the prescribed medications with a reported cure rate of $28.9 \%$ (Figure 3). The most frequent over the counter (OTC) medicine used was ranitidine followed by omeprazole. Aluminum Magnesium hydroxide was prescribed as a concomitant therapy with an antacid. The average duration of consumption was 1.65 months and $62.6 \%$ were taking medications at the time of the study. The symptoms recovery rate following OTC consumption in the reflux group was $30.6 \%$ for complete recovery and $60.2 \%$ for relative recovery. However, the remaining 9.2\% did not show any relief from symptoms with OTC consumption. Less than half of the subjects in the reflux group had not sought any medical attention. Of these, 42.3\% (182 patients) and $52 \%$ consumed OTC medications and herbal medicines, 


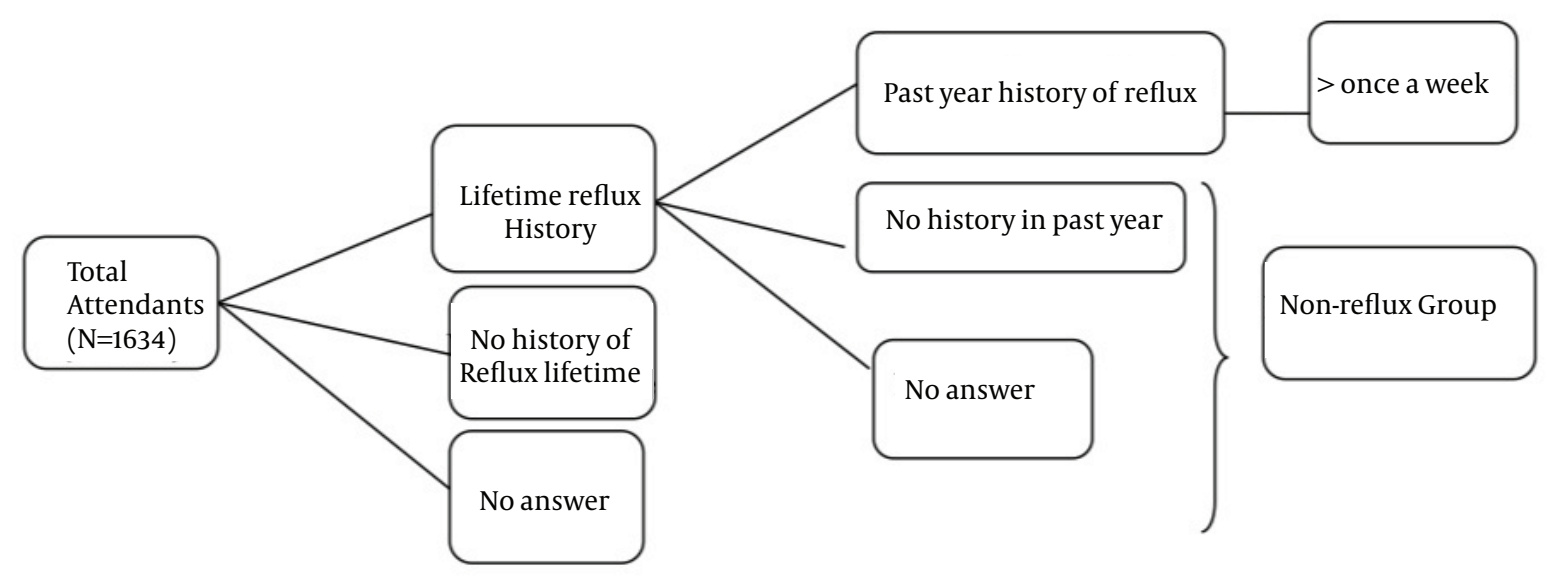

Figure 1. Prevalence of Reflux in Mashhad

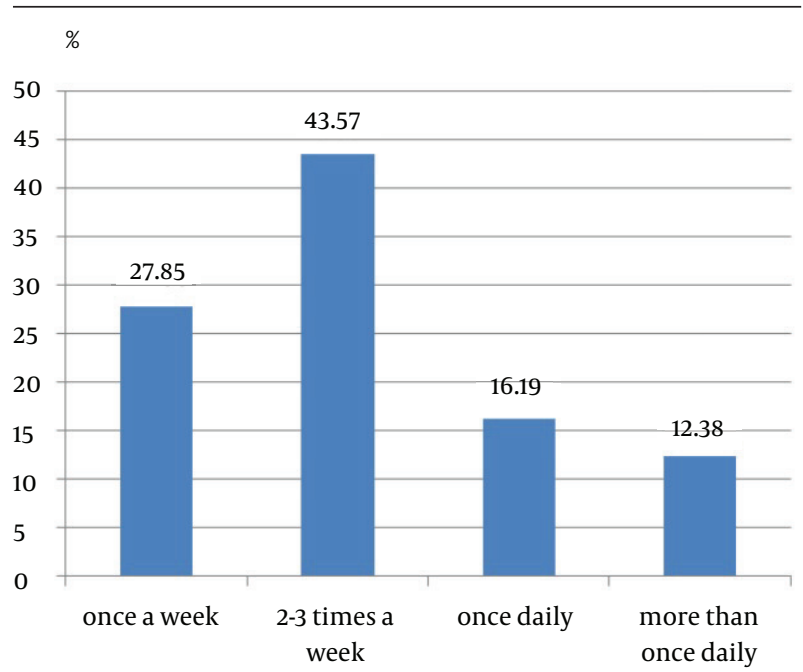

Figure 2. Frequency of Symptoms in the Gastro-esophageal Reflux Disease Group

respectively. The most common herbal medicine used was cumin (Caraway), followed by licorice and mint. Among those who had resorted to herbal medicines, $29.2 \%$ became symptom free, with $5.4 \%$ and $13.4 \%$ reporting relative and no resolution of symptoms, respectively. Furthermore, there was a significant relationship between the severity of symptoms and the rate of seeking medical consultation.

\section{Discussion}

Despite the fact that GERD is believed to be uncommon in the orient, it is prevalent and increasing both in Western countries and Iran. This disease has major effects on health, economics, and patients' health-related quality of life. Reports on the prevalence and risk factors of GERD are very inconsistent; this may be due to a lack of a uniform

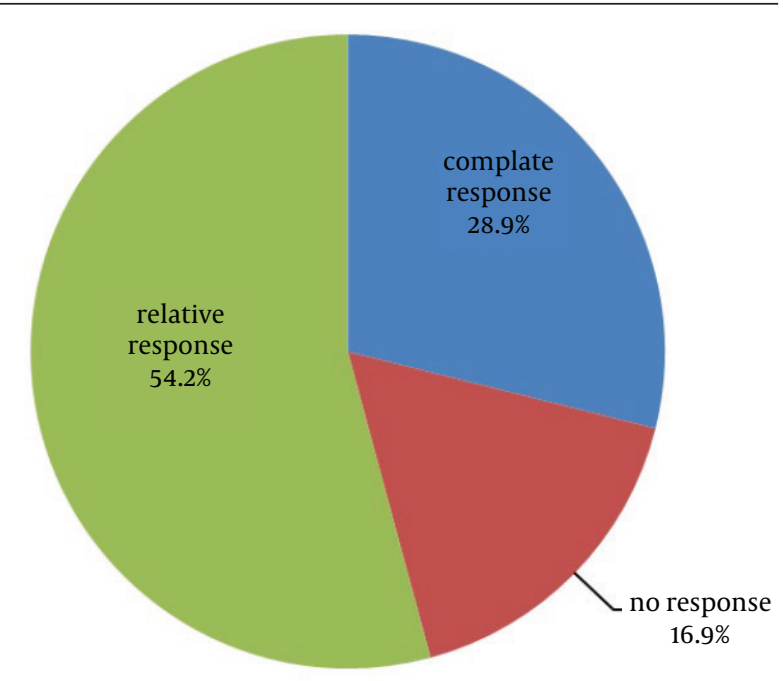

Figure 3. Response Rate to Gastro-esophageal Reflux Disease Treatment Among Participants With Gastro-esophageal Reflux Disease

definition for the disease, nonstandard diagnostic methods, differently prepared questionnaires, patients' varying habits and life styles and geographical diversity (24, 25). Given the fact that reports on the prevalence of reflux from various parts of the country are quite different, we defined a population-based study in Eastern Iran to determine the prevalence of GERD and its risk factors.

In this study, the main symptoms of GERD (i.e. heartburn and acid regurgitation), with a frequency of at least once a week, were considered as the diagnostic criteria for reflux. From the total of 1637 subjects, 420 cases met the criteria, with a calculated prevalence of $25.7 \%$. Compared to other studies around the country, the prevalence of GERD was high in Eastern Iran. Different studies from Iran have yielded greatly varying prevalence rates, ranging between $2.7 \%$ and $44 \%(10,26)$. Studies conduct- 
ed in Tehran, the capital of Iran, showed a prevalence rate of $18.2 \%$, Tabriz $26.8 \%$, and Isfahan $25 \%$. The duration of symptoms was included in some studies, ranging from once a week for six months to once a week for three months $(5,10,27)$. However, the duration of symptoms was one year for the present study. Regarding the classification strategy of this study, the participants were divided into four groups, including mild, moderate, severe, and very severe, based on their symptom severity. If subjects with mild symptoms were eliminated from the study, the reflux group would consist of 374 subjects with a prevalence rate of $22.8 \%$. However, if people with a symptom frequency of two or more times a week, or once weekly but with moderate or greater severity (severe or very severe) were included in the GERD group, the reflux group would consist of 399 subjects and a prevalence rate of $24.4 \%$.

According to three previous studies conducted in Iran there is no significant correlation between age and reflux $(5,18,19)$. This was also confirmed by our study. However, although no correlation can be found in the available literature between age and regurgitation, such a relationship is suggested for heartburn and age $(8,28)$. In our study regurgitation occurred more frequently than heartburn. Therefore, the lower incidence of heartburn may be the reason for a lack of correlation between reflux and age in the present study. A possible risk factor for GERD according to our findings is being a female since approximately $59.5 \%$ of the subjects in the reflux group were women $(P<0.005)(17,19,26)$.

Furthermore, we found a sharp correlation between the level of education and reflux $(P<0.005)(17,19,29)$. Supportive studies from Iran and Asia showed similar results, while one study suggested the opposite (30). Regurgitation, the dominant complaint reported in GERD by most studies, was the only complain in $25.7 \%$ of the reflux population in our study $(5,19,31,32)$. A significant correlation was reported in our study between over eating and GERD (33). In one study, overeating was reported as a risk factor for GERD. Furthermore, patients consuming aspirin, a nitroglycerin medication, have a higher risk for reflux, and $50 \%$ of people with chest pain are affected by $\operatorname{GERD}(34,35)$.

In different studies, the consumption of NSAIDs was shown to have a strong correlation with reflux disease. In our study, however, no statistically significant correlation could be found between these variables. Similarly, a sedentary type of living was shown to poorly correlate with reflux disease $(19,26)$. Similar to previous literature, cigarette smoking was considered as a risk factor for reflux in our study $(16,19,26)$. In contrast, tea consumption $(17,19,26,36) \mathrm{n}$ addition to fast food (36) have been introduced as common risk factors for GERD.

Interestingly, those with a history of reflux disease in their spouse proved to be at risk for reflux (19). In this study, a high prevalence rate of gastroesophageal reflux disease was found among people living in more urban areas of Mashhad. The symptoms of reflux for these areas were the same as other regions, although the rate of regurgitation was higher. Finally, there was no significant difference between the severities of symptoms among different regions in Iran. The strong point of this study was the large number of participants, which were chosen from different parts of Mashhad city with different life styles. The study could have given more definite data if the questionnaire had been filled out by an interview. We suggest prospective studies on the treatment course and complications to find out more about risk factors and use them to eliminate or decrease the complications of GERD.

\section{Acknowledgements}

We acknowledge and appreciate the financial support of the Research Council of Mashhad University of Medical Sciences, Mashhad (grant number 89365). The authors would also like to thank the Mayo Clinic for their permission to use their questionnaire in this study.

\section{Authors' Contributions}

Design: Hassan Vossoughinia and Alireza Shariati. Acquisition of data: Alireza Shariati, Mohammadjavad Shariati and Siavash Abedini. Analysis and interpretation of data: Alireza Shariati. Drafting of the manuscript: Masoumeh Salari and Siavash Abedini. Statistical analysis: Elham Mokhtari Amirmajdi. Study supervision: Hassan Saadatnia and Ahmad Khosravi Khorashad.

\section{Funding/Support}

The Mashhad University of Medical Sciences provided funding and support (research project No.89365).

\section{References}

1. Dent J, El-Serag HB, Wallander MA, Johansson S. Epidemiology of gastro-oesophageal reflux disease: a systematic review. Gut. 2005;54(5):710-7.

2. Eisen $\mathrm{G}$. The epidemiology of gastroesophageal reflux disease: what we know and what we need to know. Am J Gastroenterol. 2001;96(8 Suppl):S16-8.

3. Isolauri J, Laippala P. Prevalence of symptoms suggestive of gastro-oesophageal reflux disease in an adult population. Ann Med. 1995;27(1):67-70.

4. Kennedy T, Jones R. The prevalence of gastro-oesophageal reflux symptoms in a UK population and the consultation behaviour of patients with these symptoms. Aliment Pharmacol Ther. 2000;14(12):1589-94.

5. Nouraie M, Razjouyan H, Assady M, Malekzadeh R, NasseriMoghaddam S. Epidemiology of gastroesophageal reflux symptoms in Tehran, Iran: a population-based telephone survey. Arch Iran Med. 2007;10(3):289-94.

6. Delavari A, Moradi G, Birjandi F, Elahi E, Saberifiroozi M. The Prevalence of Gastroesophageal Reflux Disease (GERD) in the Islamic Republic of Iran: A Systematic Review. Middle East J Dig Dis. 2012;4(1):5-15.

7. Locke GR, 3rd, Talley NJ, Fett SL, Zinsmeister AR, Melton LJ, 3rd.. Prevalence and clinical spectrum of gastroesophageal reflux: a population-based study in Olmsted County, Minnesota. Gastroenterology. 1997;112(5):1448-56.

8. Bor S, Mandiracioglu A, Kitapcioglu G, Caymaz-Bor C, Gilbert RJ. Gastroesophageal reflux disease in a low-income region in Turkey. Am J Gastroenterol. 2005;100(4):759-65. 
9. Cheung TK, Lam KF, Hu WH, Lam CL, Wong WM, Hui WM, et al. Positive association between gastro-oesophageal reflux disease and irritable bowel syndrome in a Chinese population. Aliment Pharmacol Ther. 2007;25(9):1099-104.

10. Khoshbaten M. Gastro-esophageal reflux disease in northwestern Tabriz, Iran. Indian J Gastroenterol. 2003;22(4):138-9.

11. He J, Ma X, Zhao Y, Wang R, Yan X, Yan H, et al. A population-based survey of the epidemiology of symptom-defined gastroesophageal reflux disease: the Systematic Investigation of Gastrointestinal Diseases in China. BMC Gastroenterol. 2010;10:94.

12. Chen M, Xiong L, Chen H, Xu A, He L, Hu P. Prevalence, risk factors and impact of gastroesophageal reflux disease symptoms: a population-based study in South China. Scand J Gastroenterol. 2005;40(7):759-67.

13. Sandler RS, Everhart JE, Donowitz M, Adams E, Cronin K, Goodman $\mathrm{C}$, et al. The burden of selected digestive diseases in the United States. Gastroenterology. 2002;122(5):1500-11.

14. McDougall NI, Johnston BT, Kee F, Collins JS, McFarland RJ, Love AH. Natural history of reflux oesophagitis: a 10 year follow up of its effect on patient symptomatology and quality of life. Gut. 1996;38(4):481-6.

15. Jung HK. Epidemiology of gastroesophageal reflux disease in Asia: a systematic review. J Neurogastroenterol Motil. 2011; 17(1):14-27.

16. Ehsani MJ, Maleki I, Mohammadzadeh F, Mashayekh A. Epidemiology of gastroesophageal reflux disease in Tehran, Iran.J Gastroenterol Hepatol. 2007;22(9):1419-22.

17. Saberi-Firoozi M, Khademolhosseini F, Yousefi M, Mehrabani D, Zare N, Heydari ST. Risk factors of gastroesophageal reflux disease in Shiraz, southern Iran. World J Gastroenterol. 2007;13(41):5486-91.

18. Somi MH, Farhang S, Nasseri-Moghaddam S, Jazayeri ES, Mirinezhad SK, Godrati SM, et al. Prevalence and risk factors of gastroesophageal reflux disease in Tabriz, Iran. Iran J Public Health. 2008;37(3):85-90.

19. Nasseri-Moghaddam S, Mofid A, Ghotbi MH, Razjouyan H, Nouraie M, Ramard AR, et al. Epidemiological study of gastro-oesophageal reflux disease: reflux in spouse as a risk factor. Aliment Pharmacol Ther. 2008;28(1):144-53.

20. Solhpour A, Pourhoseingholi MA, Soltani F, Zarghi A, Habibi M, Ghafarnejad F, et al. Gastro-esophageal reflux symptoms and body mass index: no relation among the Iranian population. Indian J Gastroenterol. 2008;27(4):153-5.

21. Locke GR, 3rd, Talley NJ, Fett SL, Zinsmeister AR, Melton LJ, 3rd.. Risk factors associated with symptoms of gastroesophageal reflux. Am J Med.1999;106(6):642-9.
22. Kitapcioglu G, Mandiracioglu A, Caymaz Bor C, Bor S. Overlap of symptoms of dyspepsia and gastroesophageal reflux in the community. Turk J Gastroenterol. 2007;18(1):14-9.

23. Greenwald DA. Aging, the gastrointestinal tract, and risk of acidrelated disease. Am J Med. 2004;117 Suppl 5A:8S-13S.

24. Goh KL. Changing epidemiology of gastroesophageal reflux disease in the Asian-Pacific region: an overview. J Gastroenterol Hepatol. 2004;19 Suppl 3:S22-5.

25. Kang JY. Systematic review: geographical and ethnic differences in gastro-oesophageal reflux disease. Aliment Pharmacol Ther. 2004;20(7):705-17.

26. Mostaghni A, Mehrabani D, Khademolhosseini F, Masoumi SJ, Moradi F, Zare N, et al. Prevalence and risk factors of gastroesophageal reflux disease in Qashqai migrating nomads, southern Iran. World J Gastroenterol. 2009;15(8):961-5.

27. Nouraie M, Radmard AR, Zaer-Rezaii H, Razjouyan H, NasseriMoghaddam S, Malekzadeh R. Hygiene could affect GERD prevalence independently: a population-based study in Tehran. Am J Gastroenterol. 2007;102(7):1353-60.

28. Chiocca JC, Olmos JA, Salis GB, Soifer LO, Higa R, Marcolongo M, et al. Prevalence, clinical spectrum and atypical symptoms of gastro-oesophageal reflux in Argentina: a nationwide populationbased study. Aliment Pharmacol Ther. 2005;22(4):331-42.

29. Rezailashkajani M, Roshandel D, Shafaee S, Zali MR. High prevalence of reflux oesophagitis among upper endoscopies of Iranian patients. EurJ Gastroenterol Hepatol. 2007;19(6):499-506.

30. de Oliveira SS, dos Santos Ida S, da Silva JF, Machado EC. [Gastroesophageal reflux disease: prevalence and associated factors]. Arq Gastroenterol. 2005;42(2):116-21.

31. Pourshams A, Rahmani A, Hatami K. Gastroesophageal reflux disease in Iran. Govaresh. 2005;10(1):48-53.

32. Wu JC. Gastroesophageal reflux disease: an Asian perspective. $J$ Gastroenterol Hepatol. 2008;23(12):1785-93.

33. Wang JH, Luo JY, Dong L, Gong J, Tong M. Epidemiology of gastroesophageal reflux disease: a general population-based study in Xi'an of Northwest China. World J Gastroenterol. 2004; 10(11):1647-51.

34. Watson DI, Lally CJ. Prevalence of symptoms and use of medication for gastroesophageal reflux in an Australian community. World J Surg. 2009;33(1):88-94.

35. Mousavi S, Tosi J, Eskandarian R, Zahmatkesh M. Role of clinical presentation in diagnosing reflux-related non-cardiac chest pain. J Gastroenterol Hepatol. 2007;22(2):218-21.

36. Malekzadeh R, Nasseri-Moghaddam S, Sotoudeh M. Gastroesophageal reflux disease: the new epidemic. Arch Iranian Med. 2003;6(2):127-40. 